\title{
Role of transient receptor potential channels in regulating spermatozoa functions: A mini-review
}

\author{
Akshay Kumar ${ }^{1}$, Abhishek Kumar Mishra², Dilip Kumar Swain ${ }^{3}$, Vijay Singh ${ }^{1}$, Sarvajeet Yadav ${ }^{3}$ and Atul Saxena
}

1. Department of Gynaecology and Obstetrics, College of Veterinary Sciences and Animal Husbandry, U.P. Pandit Deen Dayal Upadhyaya Pashu Chikitsa Vigyan Vishwavidyalaya Evam Go Anusandhan Sansthan, Mathura, Uttar Pradesh, India; 2. College of Biotechnology, U.P. Pandit Deen Dayal Upadhyaya Pashu Chikitsa Vigyan Vishwavidyalaya Evam Go Anusandhan Sansthan, Mathura, Uttar Pradesh, India; 3. Department of Physiology, College of Veterinary Sciences and Animal Husbandry, U.P. Pandit Deen Dayal Upadhyaya Pashu Chikitsa Vigyan Vishwavidyalaya Evam Go Anusandhan Sansthan, Mathura, Uttar Pradesh, India.

Corresponding author: Dilip Kumar Swain, e-mail: dilip_swain@yahoo.com Co-authors: AK: akshay.rajawat@gmail.com; AKM: mishraakvet@gmail.com, VS: vijaysohlot1968@gmail.com, SY: yadavsarvajeet24@gmail.com, AS: dratulsaxena@rediffmail.com Received: 16-07-2018, Accepted: 08-10-2018, Published online: 23-11-2018

doi: 10.14202/vetworld.2018.1618-1623 How to cite this article: Kumar A, Mishra AK, Swain DK, Singh V, Yadav S, Saxena A (2018) Role of transient receptor potential channels in regulating spermatozoa functions: A mini-review, Veterinary World, 11(11): 1618-1623.

\begin{abstract}
Flagellar navigation along the genital tract of male and female in spermatozoa is accomplished through a number of biological, physiological, biochemical, and electrophysiological alterations in spermatozoa. These alterations are highly precise, dynamic, and regulated through a number of ion channels along with their associated pathways. Beating of flagella along with intracellular metabolism of spermatozoa is associated with fluxing of $\mathrm{Ca}++$ as well as release of $\mathrm{Ca}++$ from different sources. Calcium fluxing through the spermatozoa is mediated through sperm-specific calcium channel and also through transient receptor potential (TRP) channels which are diversified multifamily of ion channels which are activated through a number of extracellular agents such as $\mathrm{pH}$, temperature, chemicals, and pathogens. Research has shown the dynamic role of TRP channels in regulating sperm functions such as sperm chemotaxis, rheotaxis, thermotaxis, and eventually fertilization. Diversified forms of TRP and their involvement in regulation of sperm function opens new horizons of understanding of the sperm function and, in specific, issues related to infertility. This mini-review is an attempt to draw some insights into the action of TRP channels in regulating sperm fertility competence through both calcium-dependent and calcium-independent mechanisms.
\end{abstract}

Keywords: acrosome reaction, calcium, capacitation, fertilization, motility, $\mathrm{pH}$, sperm, temperature, transient receptor potential.

\section{Introduction}

Spermatozoa navigation in different chemical, physical, and fluid gradients is very complex requiring controlled and precise role of ion channels along with their downstream signal transduction pathways. Ion channels are membrane proteins being present in all living cells including sperm cells and are tightly regulated by a number of extracellular and intracellular factors [1]. From ancient times, it was believed that these are confined to excitable cells such as neurons and myocytes, but studies have shown the presence of ion channels in sperm cells and their involvement in regulation of numerous functions of sperm cells. In the recent past, the emergence of sperm ion channels has revolutionized modern understanding of sperm function and, in specific, sperm functions such as motility, capacitation, chemotaxis, and acrosomal reaction [2].

Copyright: Kumar, et al. Open Access. This article is distributed under the terms of the Creative Commons Attribution 4.0 International License (http://creativecommons.org/licenses/by/4.0/), which permits unrestricted use, distribution, and reproduction in any medium, provided you give appropriate credit to the original author(s) and the source, provide a link to the Creative Commons license, and indicate if changes were made. The Creative Commons Public Domain Dedication waiver (http://creativecommons.org/ publicdomain/zero/1.0/) applies to the data made available in this article, unless otherwise stated.
Flagellated spermatozoa exhibit kinetic motion to spot the egg to bring out fertilization which is governed through a number of intrinsic as well as extrinsic factors [3]. Key events of sperm motion in different chemical, physical, and fluid gradients are accomplished through $\mathrm{Ca}^{2+}$ and its associated signaling mechanisms [3]. Regulation of $\mathrm{Ca}^{2+}$ influx is governed through sperm-specific $\mathrm{Ca}^{2+}$ channels (CatSper) and other ion channels such as transient receptor potentials (TRPs) [2]. Species not having defined CatSper channels also exhibit $\mathrm{Ca}^{2+}$ influx and therefore hint toward the existence of other sets of mechanisms to regulate fluxing of $\mathrm{Ca}^{2+}$ into sperm cells [2]. TRP channels are large set of cation channels and regulate $\mathrm{Ca}^{2+}$ influx as well as release of $\mathrm{Ca}^{2+}$ from storage sites in spermatozoa [4].

Sperm cells are considered as dynamic cells and are the only cells to encounter their total lifespan in different physiological conditions starting from testicular microenvironment to male reproductive tract and after ejaculation in female genital tract $[5,6]$. It is very interesting to understand that how spermatozoa function in such altered and diverse environments. Sperm cells are regulated by array of fast crosstalk mechanisms and are believed to be regulated through ion channels $[5,6]$. Pharmacological, molecular, and 
electrophysiological tools have given conclusion to these hypotheses and have precisely described the role of ion channels in regulating sperm function [2]. Spermatozoa functions such as sperm motility, capacitation, hyperactivity, and chemotaxis are mediated by sperm-specific ion channels [4].

The present mini-review highlights the TRP channels and their potential involvement in regulation of sperm functions. The present review tried to address the functional involvement of TRP channels in regulation of sperm motility, hyperactivity, capacitation, chemotaxis, and thermotaxis. With these objectives, this review searched the database to find the best possible answers related to TRP channel and their function in sperm cells.

\section{Overview on TRP channels}

TRP channels were first reported in Drosophila melanogaster mutant by Cosens and Manning [7]. Montell and Rubin [8], after coding of the gene, established the homology of TRP channels with voltage-gated ion channels. TRP channels are a group of unique ion channels that serve as cellular sensors for a wide spectrum of physical and chemical stimuli [9] and constitute a distinct superfamily of ion channels which are distantly related to voltage-gated $\mathrm{K}^{+}$and $\mathrm{Na}^{+} / \mathrm{Ca}^{2+}$ superfamilies [10].

The members of TRP channels are involved in various diverse cellular functions such as vision, taste, hearing, touch, olfaction, thermal perception, and nociception [11]. Many TRP proteins play critical roles in processes such as sensory physiology, vasorelaxation, and male fertility [3]. TRP cation channels are versatile and diverse in their regulatory mechanisms, gating, and selectivity exhibiting a diverse distribution in animal kingdom starting from yeasts, flies, worms, and mice to human. Characterization and nomenclature of TRP channels have been originated from their first members being known as TRP canonical (TRPC) and were involved in phototransduction in Drosophila [12]. In sperm cells, events such as capacitation, hypermotility, chemotaxis, and fertilization are mediated by influx of $\mathrm{Ca}^{2+}$ and rise in intracellular $\mathrm{Ca}^{2+}$ concentration indicating the potential involvement of various types of TRP channels. Thirty different genes of TRP channels have been reported to date and based on sequence similarity; these are divided into following seven groups:

1. TRPC channels

2. Vanilloid TRP channels (TRPV)

3. Melastatin TRP channels (TRPM)

4. Polycystin TRP channels (TRPP)

5. Mucolipin TRP channels

6. Ankyrin TRP channels

7. No mechanoreceptor potential $\mathrm{C}$ (nompC) TRP (TRPN) channels: These channels are found in fruit flies and are associated with gating of the channel pore.

The TRP family members are related to signal transduction and are sensitive to $\mathrm{pH}$, temperature, phosphorylation, mechanical, and osmotic changes [13]. The TRPC family has attracted considerable attention due to their putative roles as store-operated and receptor-operated cation channels. In many cells, the emptying of $\mathrm{Ca}^{2+}$ stores generates a gating signal that couples intracellular $\mathrm{Ca}^{2+}$ release to the opening of store-operated channels in the plasma membrane. Li and Wang [10] reported that TRP channels are responsible for the sustained $\mathrm{Ca}^{2+}$ elevations which are necessary for normal physiological functions through store-operated channels [10].

TRP expressions are reported in both spermatogenic and mature sperm cells [14]. Protein level organization of TRP channels has been confirmed by X-ray crystallography and electron microscopy [15]. Figure- 1 summarizes the various localizations of TRP channels and their various subtypes on various compartments of spermatozoa, thus evidencing their significant role in regulating spermatozoa functions.

\section{Structure of TRP channels}

TRP channels are predicted to have six transmembrane domains with large intracellular amino and carboxyl termini similar to other ion channels [16]. A six-transmembrane helix topology (S1 through S6) with a reentrant loop between S5 and S6 forming the channel pore is a recurring structural motif [17]. These channels tetramerize to a 24-helix functional protein complex. As observed for other ion channels, TRP channel function is strongly influenced by large intracellular domains and the responsiveness to functional modulators, for example, regulation by phosphoinositides [18] or inhibition by quaternary ammonium ions [19] and venom toxins [20]. With this general overview, the present review will mostly focus on understanding the role of different TRP channels and their subtypes in regulating spermatozoa function.

\section{TRPC}

TRPCs are the first mammalian TRP subfamily discovered in 1995 in Drosophila [21]. TRPC proteins are cationic channels and mediate influx of $\mathrm{Ca}^{2+}, \mathrm{Na}^{+}$, and $\mathrm{K}^{+}$on voltage-dependent manner [22]. There are seven TRPC subunits, and they are functionally localized in spermatozoa. Table- 1 enlists the different types of TRPC channels in spermatozoa [14,23-28].

Oocyte/egg-sperm interaction involves chemotaxis, capacitation, and hyperactivity of spermatozoa, eventually leading to sperm head fusion and acrosomal reaction (AR) [29]. Studies have shown the involvement of TRPC and its subtype in mediating $\mathrm{Ca}^{2+}$ influx. In mouse model, TRPC2 is involved in $\mathrm{Ca}^{2+}$ influx while TRPC3 in Caenorhabditis elegans [30]. Functional studies have revealed that $\mathrm{Ca}^{2+}$ influx is mediated by TRPC2, and in specific, this is triggered by ZP3 [29].

Various localizations of TRPC in spermatozoa have given the indications that they mediate complex series of signaling in spermatozoa, and various compartments are involved in regulating $\mathrm{Ca}^{2+}$ influx. 


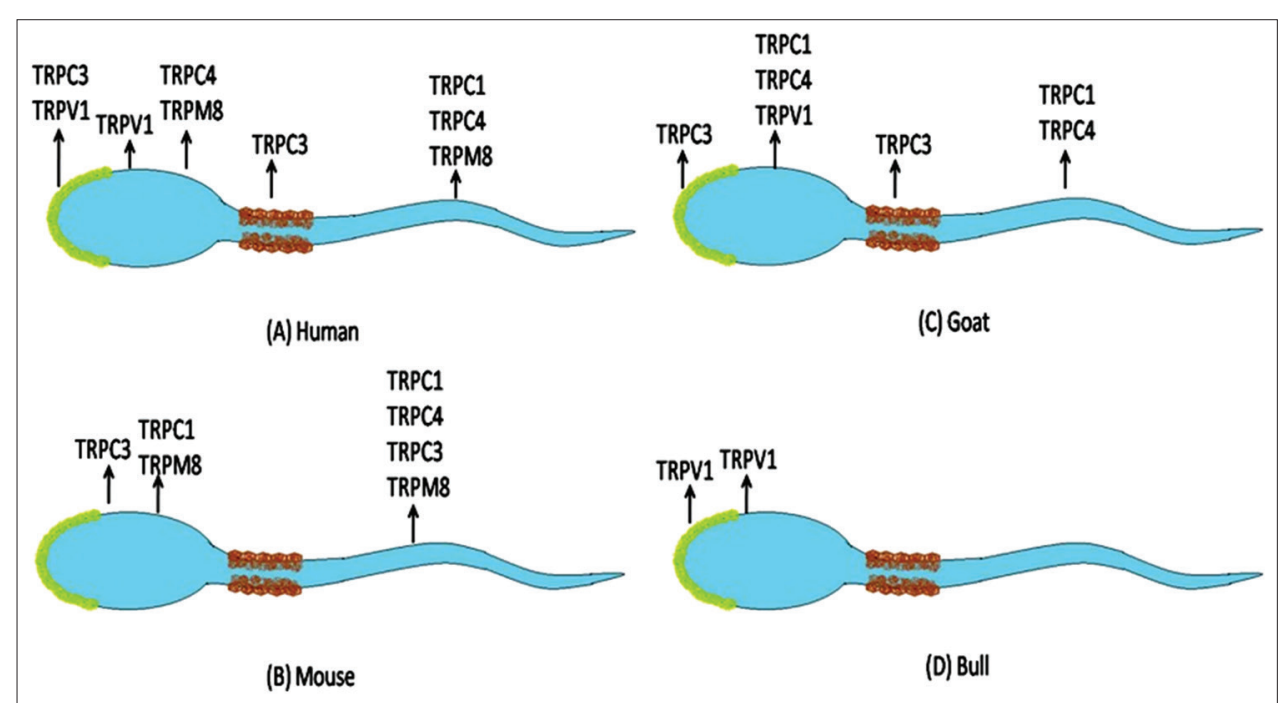

Figure-1: Photomicrograph depicting the functional localization of various types of transient receptor potential (TRP) channels and their subtypes on spermatozoa of various species of animals (A: Human; B: Mouse; C: Goat; and D: Bull). TRPC - TRP canonical; TRPV - TRP vanilloid; TRPM: TRP melastatin (Figure was designed by DKS, AK, and AKM).

Table-1: Localization of different types of TRPC on spermatozoa (designed by AK and AKM).

\begin{tabular}{llc}
\hline Subtype of TRPC & Localization on spermatozoa & References \\
\hline TRPC1 & Head and flagella of mouse, human, and goat spermatozoa & {$[24,25]$} \\
TRPC2 & Anterior part of mouse sperm & {$[26]$} \\
TRPC3 $(109 \mathrm{kDa})$ & $\begin{array}{l}\text { Post-acrosomal region and flagella in mouse spermatozoa; acrosomal region and } \\
\text { midpiece in human and goat spermatozoa }\end{array}$ & {$[14,25,27]$} \\
TRPC4 & $\begin{array}{l}\text { Head and flagella of human and goat spermatozoa and flagella of mouse sperm } \\
\text { TRPC5 }(111 \mathrm{kDa})\end{array}$ & $\begin{array}{l}\text { Head and flagellum of human sperm } \\
\text { TRPC6 }(140 \mathrm{kDa})\end{array}$ \\
TRPC7 & Flagella of mouse, human, goat sperm, and head of human and goat spermatozoa & {$[14]$} \\
\hline
\end{tabular}

$\mathrm{TRP}=$ Transient receptor potential, TRPC=Canonical transient receptor potential

Pyr3 which acts as an antagonist of TRPC3 can inhibit sperm motility and accelerate capacitation-associated protein tyrosine phosphorylation in a time- and dose-dependent manner regardless of the presence or absence of $\mathrm{Ca}^{2+}$ in the incubation medium [27]. TRPC channel blocker SKF96365 exerted similar effects on mouse sperm motility and capacitation, indicating a potential role of TRPC in mediating sperm motility and capacitation through $\mathrm{Ca}^{2+}$ signaling.

$T R P V$

The TRPV channels are constituted by six members activated by physical and chemical stimuli [9]. TRPV is sensitive to changes in $\mathrm{pH}$, osmolarity, ion changes, and high temperature. Various subtypes of TRPV are sensitive to different temperature gradients and get activated to mediate $\mathrm{Ca}^{2+}$ influx. TRPV1 to TRPV4 are $\mathrm{Ca}^{2+}$ permeable, non-selective cationic channels and are sensitive to endogenous as well as exogenous ligands [31]. TRPV1 is the most studied member of this group, and it is found in urinary bladder [32] and in the reproductive system [33] along with other tissues. Caterina and Julius [34] established the two agonists of this channel that is capsaicin and resiniferatoxin. Anandamide (AEA) is a potent agonist of TRPV1 and also acts as an endovanilloid. Through the activation of TRPV1, AEA reduces mitochondrial activity, and hence, it affects the motility of human sperm. It also inhibits capacitation-induced acrosome reaction [35]. These effects of AEA were prevented by the CB1R antagonist SR141716A, leading to the suggestion that they required $\mathrm{CB} 1 \mathrm{R}$ activation while capsazepine promotes spontaneous acrosomal reaction [35] and its use inhibited sperm-oocyte fusion [36]. SR141716A (selective CB1 cannabinoid inverse agonist/antagonist) and SR144528 (selective antagonist of the CB2 cannabinoid receptor) act as potent antagonist of TRPV1 channel [35]. TRPV1 activates endocannabinoid system and is sensitive to high temperature (up to $42^{\circ} \mathrm{C}$ ) and low $\mathrm{pH}$. Its sensitivity is reported to piperine and allicin is modified by the presence of ethanol, nicotine, or changes in phosphatidylinositol 4,5-bisphosphate levels [37].

TRPV2 channel shows $50 \%$ similarity in amino acids to TRPV1 and gets activated at approximately $52^{\circ} \mathrm{C}$, while TRPV 3 and TRPV4 are $40-50 \%$ homologous with TRPV1. The activator of TRPV3 is aromatic substances like cloves [38], and temperature ranges from 34 to $39^{\circ} \mathrm{C}$ [39], while activator of TRPV4 osmotic changes phorbol esters [40] and temperature $\left(25-34^{\circ} \mathrm{C}\right)$ [39]. TRPV5 and 6 show the least sensitivity to temperature while very selective to $\mathrm{Ca}^{2+}$ and can be modulated by $\mathrm{Ca}^{2+}$ [18]. TRPV6 regulates extracellular $\mathrm{Ca}^{2+}$ concentration of the epididymal duct which 
Table-2: Localizations of different types of TRPV on spermatozoa (designed by AK and AKM).

\begin{tabular}{llr}
\hline Subtype of TRPV & Localization on spermatozoa & References \\
\hline TRPV1 & Acrosomal and post-acrosomal regions of boar, bull, and human spermatozoa & {$[35,38,41]$} \\
TRPV5 & Rat spermatozoa (not specified) & {$[10]$} \\
TRPV6 & Epididymal epithelium but not in mouse spermatozoa & {$[3]$} \\
\hline
\end{tabular}

TRPV=Vanilloid transient receptor potential

Table-3: Localizations of different types of TRPM on spermatozoa (designed by AK and AKM).

\begin{tabular}{llr}
\hline Subtype of TRPM & Localization on spermatozoa & References \\
\hline TRPM3, TRPM4, TRPM5, TRPM6, and TRPM7 & Rat spermatogenic cell and spermatozoa & {$[10,46]$} \\
TRPM8 & Head and flagellum of mouse and human spermatozoa & {$[45,46]$} \\
\hline
\end{tabular}

TRPM: Transient receptor potential melastatin

is essential for motility and fertilization capacity of spermatozoa [3]. Table-2 depicts the presence of different types of TRPV on spermatozoa $[3,10,35,38,41]$.

\section{TRPMs}

TRPM is a member of TRP superfamily and is closely related to the TRPC and TRPV. This subfamily is comprised of eight members (TRPM1 to TRPM8). TRPM1 is first reported in 1998 in tumor suppressor protein melanocytes. TRPM2 as an adenosine diphosphate ribose-activated channel of macrophages; TRPM3 is a hypoosmolarity and sphingosine-activated channel; TRPM4 and TRPM5 are calcium-activated non-selective cation channels; TRPM6 and TRPM7 are magnesium permeable and magnesium-modulated cation channels; and TRPM8 has been described as a cold receptor [42]. TRPM7 is responsible for $\mathrm{Zn}^{2+}$ homeostasis in male reproductive tract, and its role is described in sperm maturation [10,42]. TRPM8 is $\mathrm{Ca}^{2+}$ permeable non-selective cation channel and is regulated by androgens. It is also associated with $\mathrm{Ca}^{2+}$ homeostasis in the prostate epithelium $[42,43]$. Activation of TRPM8 in capacitated mouse spermatozoa reduced their capacity to undergo the progesterone-induced AR [44]. TRPM8 (approx $130 \mathrm{kDa}$ ) channels could be involved in cell signaling events such as thermotaxis or chemotaxis $[42,45]$. In mouse spermatozoa, TRPM8 detects temperature changes and may influence the AR altering intracellular calcium levels. TRPM8 activation significantly increases $\left[\mathrm{Ca}^{2+}\right]$ and also induces the AR $[42,45]$. Table-3 depicts the presence of different types of TRPM and their functional localizations on different parts of spermatozoa $[10,45,46]$.

\section{TRPPS}

TRPP subfamily is associated with polycystic kidney disease (PKD) in the human which is under the influence of autosomal dominant gene. This channel is made up of two proteins, namely PKD-1 and PKD-2. PKD-1 is known as TRPP1 and acts as a receptor, while PKD-2 is known as TRPP2 and acts as an ion channel. The PKD2-like subgroup contains three homologous proteins - PKD2, PKD2L1, and PKD2L2 and is referred to as TRPP2, TRPP3, and TRPP5 [25].
Table-4: Localizations of different types of TRPP on spermatozoa (designed by AK and AKM).

\begin{tabular}{llc}
\hline $\begin{array}{l}\text { Subtype of } \\
\text { TRPP }\end{array}$ & $\begin{array}{l}\text { Localization on } \\
\text { spermatozoa }\end{array}$ & References \\
\hline TRPP3 & $\begin{array}{l}\text { Mouse testis; human } \\
\text { spermatozoa }\end{array}$ & {$[25,51]$} \\
TRPP5 & $\begin{array}{l}\text { Mouse and human } \\
\text { spermatozoa }\end{array}$ & {$[25,51]$} \\
\hline
\end{tabular}

TRPP: Transient receptor potential polycystin

Polycystin-1 forms a complex with Polycystin-2 ion channel or protein to regulate various biological processes [47].

PKD and receptor for egg jelly (PKDREJ) expression have been detected only in the mammalian testis, where it is restricted to the spermatogenic lineage and retained in mature sperm. PKDREJ is a specific domain detected only in mammalian testis, head of mature spermatozoa, and spermatogenic lineage [48]. A PKDREJ transcript was detected in spermatogenic cells by in situ hybridization with mouse testicular tissue. Polycystin 1 and 2 proteins are detected in the spermatozoa head of the sea urchin and responsible for acrosomal reaction [49]. Human subjects with autosomal PKD due to defects in polycystin (PKD) genes have necrospermia and immotile sperm along with seminal vesicle and ejaculatory duct cysts [50]. TRPP proteins also have been found to be associated with regulation of human sperm motility including other mammals [51]. Table-4 summarizes the localizations of different types of TRPP at different localizations of spermatozoa [25,51].

\section{Conclusion}

TRP channels and their various subtypes are involved in regulating spermatozoa functions through regulating calcium homeostasis along with other ion channels. These channels regulate vital functions of spermatozoa such as sperm motility, hypermotility, chemotaxis, capacitation, thermotaxis, and acrosome reaction. TRP channels also make the spermatozoa competent enough to respond to various extracellular stimuli and eventually mediate their function. Understanding the different types of TRPs will help further the science to improve sperm functions as well 
as will help in the development of suitable measures for the treatment of infertility.

\section{Authors' Contributions}

$\mathrm{AK}$ and $\mathrm{AKM}$ designed and framed the manuscript as a part of their research under the supervision of DKS. VS, AS, and SY carried out the proof reading and finalized the manuscript and guided entirely during the preparation of this manuscript. DKS designed the concept and finalized the manuscript for publication. All authors read and approved the final manuscript.

\section{Acknowledgments}

The authors would like to thank the ViceChancellor, U.P. Pt. Deen Dayal Upadhyaya Pashu Chikitsa Vigyan Vishwavidyalaya, Mathura-281001, and the Dean, College of Veterinary Science and Animal Husbandry, Mathura-281001, India for providing necessary facilities to carry out this work.

\section{Competing Interests} interests.

The authors declare that they have no competing

\section{References}

1. Darszon, A., Labarca, P., Nishigaki, T. and Espinosa, F, (1999) Ion channels in sperm physiology. Physiol. Rev., 79(2): 481-510.

2. Lishko, P.V., Kirichok, Y., Ren, D., Navarro, B., Chung, J.J. and Clapham, D.E. (2012) The control of male fertility by spermatozoan ion channels. Ann. Rev. Physiol., 74: 453-475.

3. Weissgerber, P. and Kriebs, U. (2011) Male fertility depends on $\mathrm{Ca}^{2+}$ absorption by TRPV6 in epididymal epithelia. Sci. Signal., 4(171): 27-33.

4. Darszon, A., Sánchez-Cárdenas, C., Orta, G., Sánchez-Tusie, A.A., Beltrán, C., López-González, I., Granados-González, G. and Treviño, C.L. (2012) Are TRP channels involved in sperm development and function? Cell Tissue Res., 349(3): 749-764.

5. Ng, K.Y., Mingels, R., Morgan, H., Macklon, N. and Cheong, Y. (2018) In vivo oxygen, temperature and $\mathrm{pH}$ dynamics in the female reproductive tract and their importance in human conception: A systematic review. Hum. Reprod. Updat., 24(1): 15-34.

6. Shum, W.W.C., Ruan, Y.C., Da Silva, N. and Breton, S. (2011) Establishment of cell-cell crosstalk in the epididymis: Control of luminal acidification. J. Androl., 32(6): 576-586.

7. Cosens, D.J. and Manning, A. (1969) Abnormal electroretinogram from a Drosophila mutant. Nature, 224(5216): 285.

8. Montell, C. and Rubin, G.M. (1989) Molecular characterization of the Drosophila TRP locus: A putative integral membrane protein required for phototransduction. Neuron, 2(4): 1313-1323.

9. Zheng, J. (2013) Molecular mechanism of TRP channels. Compr. Physiol., 3(1): 221-242.

10. Li, S. and Wang, X. (2010) Distribution profiles of transient receptor potential melastatin- and vanilloid-related channels in rat spermatogenic cells and sperm. Mol. Biol. Rep., 37(3): 1287-1293.

11. Latorre, R., Zaelzer, C. and Brauchi, S. (2009) Structurefunctional intimacies of transient receptor potential channels. Q. Rev. Biophys., 42(3): 201-246.

12. Clapham, D.E. (2003) TRP channels as cellular sensors.
Nature, 426(6996): 517-524.

13. Suh, B.C. and Hille, B. (2008) PIP2 is a necessary cofactor for ion channel function: How and why? Ann. Rev. Biophys., 37(9): 175-195.

14. Castellano, L.E., Trevino, C.L., Rodriguez, D., Serrano, C.J., Pacheco, J., Tsutsumi, V., Felix, R. and Darszon, A. (2003) Transient receptor potential (TRPC) channels in human sperm: Expression, cellular localization and involvement in the regulation of flagellar motility. FEBS Lett., 541(1-3): 69-74.

15. Hellmich, R.G. and Ute, A. (2014) Structural biology of TRP channels. Mammalian transient receptor potential (TRP) cation channels. Handb. Exp. Pharmacol., 223: 963-990.

16. Liao, M., Cao, E., Julius, D. and Cheng, Y. (2013) Structure of the TRPV1 ion channel determined by electron cryo-microscopy. Nature, 504(7478): 107-112.

17. She, J., Guo, J., Chen, Q., Zeng, W., Jiang, Y. and Bai, X.C. (2018) Structural insights into the voltage and phospholipid activation of the mammalian TPC1 channel. Nature, 556(7699): 130-134.

18. Nilius, B., Owsianik, G. and Voets, T. (2008) Transient receptor potential channels meet phosphoinositides. EMBO J., 27(21): 2809-2816.

19. Jara-Oseguera, A., Simon, S.A. and Rosenbaum, T. (2008) TRPV1: On the road to pain relief. Curr. Mol. Pharm., 1(3): 255-269.

20. Siemens, J., Zhou, S., Piskorowski, R., Nikai, T., Lumpkin, E.A., Basbaum, A.I., King, D. and Julius, D. (2006) Spider toxins activate the capsaicin receptor to produce inflammatory pain. Nature, 447(1164): 208-212.

21. Zhu, X., Chu, P.B., Peyton, M. and Birnbaumer, L. (1995) Molecular cloning of a widely expressed human homolog for the Drosophila TRP gene. FEBS Lett., 373(3): 193-198.

22. Beech, D.J. (2011) Integration of transient receptor potential canonical channels with lipids. Acta Physiol., 2(2): 227-237

23. Zhu, G., Xie, C., Yang, Z., Wang, Y., Chen, D. and Wang, X. (2018) Expression of TRPC5 is decreased in the sperm of patients with varicocele-associated asthenozoospermia. Biomed. Rep., 8(6): 529-534.

24. Darszon, A., Nishigaki, T., Beltran, C. and Trevino, C.L. (2011) Calcium channels in the development, maturation and function of spermatozoa. Physiol. Rev., 1(4): 1305-1355.

25. Kumar, P.G. and Shoeb, M. (2011) The role of TRP ion channels in testicular function. Adv. Exp. Med. Biol., 704: 881-908.

26. Frankenberg, S., Schneider, N.Y., Fletcher, T.P., Shaw, G. and Renfree, M.B. (2011) Identification of two distinct genes at the vertebrate TRPC2 locus and their characterisation in a marsupial and a monotreme. BMC Mol. Biol., 12: $39-45$.

27. Ru, Y., Zhou, Y. and Zhang, Y. (2015) Transient receptor potential-canonical 3 modulates sperm motility and capacitation-associated protein tyrosine phosphorylation via $\left[\mathrm{Ca}^{2+}\right]$ i mobilization. Acta Biochem. Biophys. Sin., 47(6): 404-413.

28. Numaga, T. and Wakamori, M. (2007) TRPC7. Handb. Exp. Pharmacol., 179: 143-151.

29. Tosti, E. and Ménézo, Y. (2016) Gamete activation: Basic knowledge and clinical applications. Hum. Reprod., 22(4): 420-439.

30. Krauchunas, A.R., Marcello, M.R. and Singson, A. (2016) The molecular complexity of fertilization: Introducing the concept of a fertilization synapse. Mol. Reprod. Dev., 83(5): 376-386.

31. Nilius, B., Owsianik, G., Voets, T. and Peters, J.A. (2007) Transient receptor potential cation channels in disease. Physiol. Rev., 87(1): 165-217.

32. Szallasi, A., Conte, B., Goso, C., Blumberg, P.M. and Manzini, S. (1993) Characterization of a peripheral 
vanilloid (capsaicin) receptor in the rat urinary bladder. Life Sci., 1993: 52-58.

33. Dorr, J. and Fecher-Trost, C. (2011) TRP channels in female reproductive organs and placenta. Adv. Exp. Med. Biol., 704: 909-928.

34. Caterina, M.J. and Julius, D. (2001) The vanilloid receptor: A molecular gateway to the pain pathway. Ann. Rev. Neurosci., 24(1): 487-517.

35. Gervasi, M.G. and Osycka-Salut, C. (2011) Anandamide capacitates bull spermatozoa through CB1 and TRPV1 activation. PLoS One, 6(2): 16993-17003.

36. Francavilla, F. and Battista, N. (2009) Characterization of the endocannabinoid system in human spermatozoa and involvement of transient receptor potential vanilloid 1 receptor in their fertilizing ability. Endocrinology, 150(10): 4692-4700.

37. Rizopoulos, T., Papadaki-Petrou, H. and Assimakopoulou M. (2018) Expression profiling of the transient receptor potential vanilloid (TRPV) channels 1, 2, 3 and 4 in mucosal epithelium of human ulcerative colitis. Cells, 7(6): 61-72.

38. Xu, H. and Delling, M. (2006) Oregano, thyme and clove-derived flavors and skin sensitizers activate specific TRP channels. Nat. Neurosci., 9(5): 628-635.

39. Jeong, J.H., Lee, D.K., Liu, S.M., Chua, S.C., Schwartz, G.J. and Jo, Y.H. (2018) Activation of temperature-sensitive TRPV1-like receptors in ARC POMC neurons reduces food intake. PLoS Biol., 16(4): 2004399-2004406.

40. Watanabe, H. and Davis, J.B. (2002) Activation of TRPV4 channels (hVRL-2/mTRP12) by phorbol derivatives. $J$. Biol. Chem., 277(16): 13569-13577.

41. Bernabo, N. and Pistilli, M.G. (2010) Role of TRPV1 channels in boar spermatozoa acquisition of fertilizing ability. Mol. Cell. Endocrinol., 323(2): 224-231.
42. Zierler, S., Hampe, S. and Nadolni, W. (2017) TRPM channels as potential therapeutic targets against pro-inflammatory diseases. Cell Calcium, 67: 105-115.

43. Yang, Z., Wang, X., Zhu, G., Zhou, Z., Wang, Y., Chen, D. and Meng, Z. (2012) Effect of surgical castration on expression of TRPM8 in urogenital tract of male rats. Mol. Biol. Rep., 39: 4797-4802.

44. Gibbs, G.M. and Orta, G. (2011) Cysteine-rich secretory protein 4 is an inhibitor of transient receptor potential M8 with a role in establishing sperm function. Proc. Natl. Acad. Sci. U. S. A., 108(17): 7034-7039.

45. De Blas, G.A. and Darszon, A. (2009) TRPM8, a versatile channel in human sperm. PLoS One, 4(6): 6095-6102.

46. Martinez-Lopez, P. and Trevino, C. (2011), TRPM8 in mouse sperm detects temperature changes and may influence the acrosome reaction. J. Cell. Physiol., 226(6): 1620-1631.

47. Sutton, K.A. and Jungnickel, M.K. (2006) Functional characterization of PKDREJ, a male germ cell-restricted polycystin. J. Cell. Physiol., 209(2): 493-500.

48. Butscheid, Y., Chubanov, V., Steger, K., Meyer, D., Dietrich, A. and Gudermann, T. (2006) Polycystic kidney disease and receptor for egg jelly is a plasma membrane protein of mouse sperm head. Mol. Reprod. Dev., 73(3): 350-360.

49. Neill, A.T. and Vacquier, V.D. (2004) Ligands and receptors mediating signal transduction in sea urchin spermatozoa. Reproduction, 127(2): 141-149.

50. Vora, N., Perrone, R. and Bianchi, D.W. (2008) Reproductive issues for adults with autosomal dominant polycystic kidney disease. Am. J. Kidney Dis., 51(2): 307-318.

51. Sutton, K.A. and Jungnickel, M.K. (2008) A polycystin-1 controls postcopulatory reproductive selection in mice. Proc. Natl. Acad. Sci. U. S. A., 105(25): 8661-8666. 